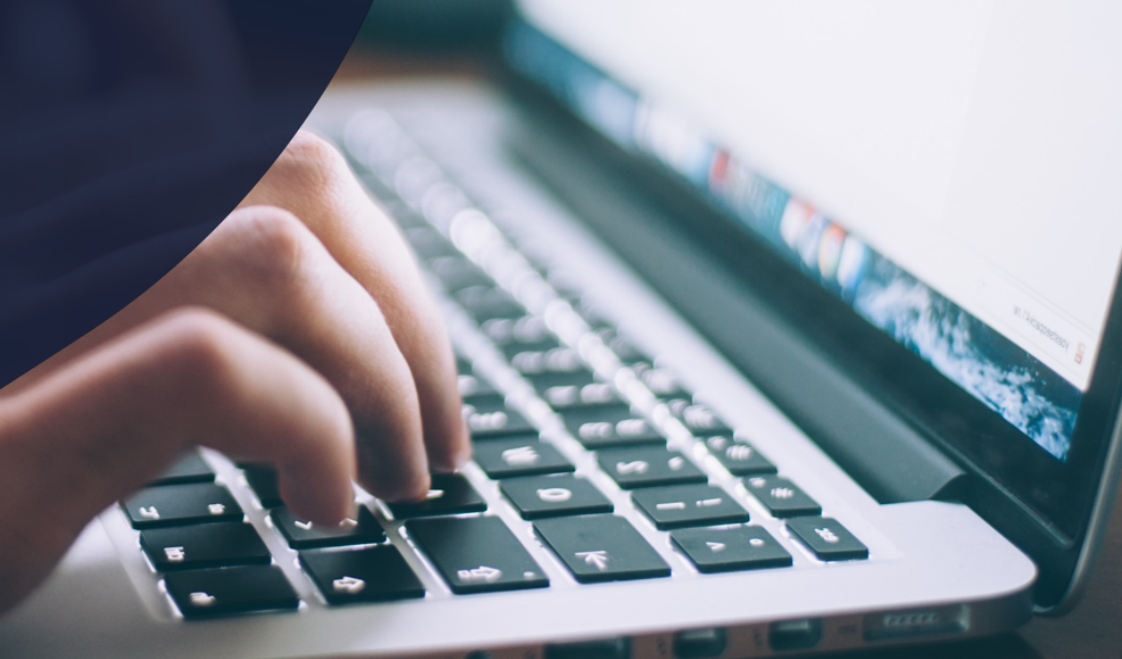

\section{Children's exposure to sexually explicit content: Parents' awareness, attitudes and actions}

\author{
PREPARED BY DR EDGAR PACHECO AND \\ NEIL MELHUISH
}

\section{What is this about?}

This report presents findings from a larger quantitative study about parenting, digital technologies and online risks. It focuses on parents and caregivers' awareness and attitudes regarding their child's exposure to sexually explicit content online. The study was conducted in New Zealand based on a nationally representative sample.

Through this report, Netsafe seeks to provide the online safety community and public with research-based evidence regarding the extent and impact of online risks and harm. Children and young people have been a key part of our research agenda since becoming the Approved Agency under the Harmful Digital Communications Act 2015, leading to the publication of reports on teens' online sharing of nudes, and the emotional and behavioural impact of unwanted digital communication on young people (see Netsafe, 2017, 2018c). While digital technologies offer young people opportunities - such as entertainment, socialising, and learning (Netsafe, 2018a) - the

\section{Summary of findings}

- Parents' main online concerns are their children sharing nudes of themselves, being treated in a hurtful way, and seeing sexually explicit content.

- 1 in 5 parents said their children were exposed to sexually explicit content online in the prior year.

- Parents reported children's exposure to sexually explicit content increased with age; and exposure to sexually explicit content was more common among boys.

- The main reasons parents gave for their child's exposure to this content were: it popped up on the screen/device, curiosity, and accidental access.

- $39 \%$ of parents said they stayed calm after finding their children were exposed to sexually explicit content while $22 \%$ were angry, and $10 \%$ ignored the situation.

- Most parents believe they know what to do and say if their children access or are exposed to sexually explicit content.

- After a situation occurred, most parents (72\%) talked with their children about sexually explicit content on the internet.

- Most parents are confident talking with their children about pornography, while 2 in 10 feel embarrassed. Over half said they discuss sex education and sexuality with their children, while 3 in 10 do not.

- Half of parents know where to access information and resources about children and pornography, while 4 in 10 do not. 
potential for them to be exposed to sexually explicit content online is a matter of concern. For Netsafe understanding this phenomenon is of interest due to the risks and potential harm it involves. Recently, New Zealand-based research has concentrated on the exposure and consumption of pornographic material among adolescents (see Office of Film and Literature Classification, 2018). Our study complements these efforts by exploring parents' level of awareness and attitudes regarding children's exposure to sexual content online.

Parents are key players in relation to the online safety of their children. However, while evidence shows that New Zealand teens regard their parents as the first line of support in dealing with online risks and challenges (see Netsafe, 2018b), parents seem to underestimate or be unaware of the frequency of such risks (Byrne, Katz, Lee, Linz, \& Mcllrath, 2014; Livingstone, Haddon, Görzig, \& Ólafsson, 2011). What is more, little is still known about parents' behaviours and actions when their children have been exposed to online risks (Rothman, Paruk, Espensen, Temple, \& Adams, 2017). This study seeks to address the gap in New Zealand. By exploring parents' attitudes and behaviours, Netsafe believes this report makes a useful contribution to the understanding of digital parenting in New Zealand. It can inform service delivery and support parents' efforts towards fostering a positive online experience as part of their children's healthy development.

\section{What we know so far}

A significant body of international research has explored children and adolescents' exposure to sexually explicit content, especially pornographic material. Reviews of available empirical research have been conducted in recent years (see Owens, Behun, Manning, \& Reid, 2012; Peter \& Valkenburg, 2016; Short, Black, Smith, Wetterneck, \& Wells, 2012). Overall, these reviews found that measures of children and adolescents' exposure to and use of pornography differ among studies, and that evidence regarding the impact of sexually explicit content on minors is inconclusive (Peter \& Valkenburg, 2016). The last point is a matter of current academic debate (see Campbell, 2016; Dines, 2018; Flood, 2009; Horvath et al., 2013; Lim, Carrotte, \& Hellard, 2016; Livingstone, 2017; McCormack \& Wignall, 2017). Contrasting evidence about exposure to and the impact of sexually explicit content on young people might be due, in part, to differences in methodological approaches applied and philosophical assumptions about the topic.

In New Zealand, a recent study published by the Office of Film and Literature Classification (2018) found that about two thirds of teenagers aged 14 to 17 years old have been exposed to pornography at some point in their lives. The study defines pornography as "explicit images, video, or movies of a person or people having real sex or doing sexual things and you can see their genitals (e.g. penis, vagina)." (Office of Film and Literature Classification, 2018, p. 16). It also found that 1 in 4 teens first saw pornographic content before the age of 12 and that $71 \%$ were not seeking pornography when they saw it for the first time. In terms of gender, the study found that access to this material was more common among male teenagers (75\%) than females (58\%) (Office of Film and Literature Classification, 2018).

In addition, parents' awareness and behaviours about children and teens' exposure to sexually explicit content have received some research attention. A study on 9 to 16 -year-olds from 25 European countries (see Livingstone et al., 2011) found that $40 \%$ of parents of children who reported to have seen sexually explicit content indicated that their children did not experience it. Meanwhile, 35\% were aware of their child's experience, and $26 \%$ said they did not know whether their child had been exposed. A US-based study (see Byrne et al., 2014), on the other hand, found that parents tend to underestimate children's accidental exposure to sexually explicit content. Also, when parents find out that their child has seen such content their reactions tend to be: a) angry, shaming, or punitive; b) calm and factual; c) ignoring, minimising, or 
denying that it happened; d) panic or fear; and e) lying about the incident (see Rothman et al., 2017).

Some of the actions usually taken by parents to keep children safe online include communicating with them, restricting and monitoring their internet use, as well as using filtering/blocking software (Anderson, 2016; Livingstone et al., 2011). A recent Australiabased study ${ }^{1}$ found that most parents (61\%) talked with their child after finding out the pornographic content was accessed. Less common actions were to monitor internet use (29\%), and install internet filters (20\%). In New Zealand, research on parents' attitudes and actions regarding this topic has received little attention with efforts mainly focused on children's personally reported experiences, through a range of media (Broadcasting Standards Authority \& NZ On Air, 2015; Office of Film and Literature Classification, 2018). This study seeks to close the gap by providing quantitative evidence about parents' awareness, attitudes, and actions about their children's exposure to sexually explicit content.

\section{What we did}

We conducted a quantitative survey with parents/whānau (and caregivers) of children aged 9 to 17 years old. The survey was informed by the Global Kids Online ${ }^{2}$ (GKON) framework and other prior research on the topic (Rothman et al., 2017; Zurcher, 2017). We also sought feedback from relevant stakeholders to improve the questionnaire.

Our intention was to gather statistical insights about parents' awareness and attitudes towards their child's access and exposure to sexually explicit content, both deliberately and/or accidentally, in the prior year. Our working definition of sexually explicit content was:
Any online content (e.g. pictures, photos, videos) that is sexually explicit, for instance material showing people naked, partially naked in a sexually suggestive situation and/or people having sex.

This definition includes mainstream pornography but was not limited to it. We sought participation of parents most involved in their child's online experiences. Where there was more than one child in the age group in the household, we asked parents to answer the survey with only one of their children in mind. Fieldwork took place during August and September 2018. The survey, which was administered by Colmar Brunton, collected representative data in terms of gender, age, ethnicity, and location.

A total of 2061 parents participated in the study. The margins of error are $\pm 2.2 \%$ at $95 \%$ confidence for the whole sample, and a maximum of $\pm 6.6 \%$ for specific sub-groups. We provided parents with information about the study and asked for their consent to participate, assuring them that their data will be kept confidential. We acknowledge that any measure based on self-reported data is an inherent limitation.

Note that percentages in figures and tables may not total exactly $100 \%$ due to rounding or because survey participants were allowed to choose multiple answers to some questions.

\section{What we found}

This section describes the main findings from our survey. These findings are presented according to the six-question module we developed for the study.

\section{PARENTS' MAIN ONLINE SAFETY CONCERNS}

The first question asked all parents about the main concerns they had regarding the online safety of their child. As Table 1 shows, the main concerns pointed out by parents were:

\footnotetext{
${ }^{1}$ See "Parenting and pornography: Findings from Australia, New Zealand, and the United Kingdom" at https://www.esafety.gov.au/research 2 https://globalkidsonline.net/
} 
their child sharing nudes of themselves (59\%), being treated in a hurtful way (51\%) and seeing sexually explicit content (49\%). Note that participants could choose multiple responses.

Table 1. Parents' main online safety concerns

\begin{tabular}{|l|l|}
\hline Parents' main online concerns & $\%$ \\
\hline $\begin{array}{l}\text { Sharing nude images or video of themselves } \\
\text { with other people }\end{array}$ & $59 \%$ \\
\hline $\begin{array}{l}\text { Being treated in a hurtful or nasty way on the } \\
\text { internet by someone }\end{array}$ & $51 \%$ \\
\hline $\begin{array}{l}\text { Seeing sexual images or video of someone } \\
\text { naked }\end{array}$ & $49 \%$ \\
\hline $\begin{array}{l}\text { Meeting anyone face-to-face that your child } \\
\text { first got to know on the internet }\end{array}$ & $44 \%$ \\
\hline $\begin{array}{l}\text { Having their personal data accessed or } \\
\text { misused by someone else }\end{array}$ & $42 \%$ \\
\hline $\begin{array}{l}\text { Treating someone else in a hurtful or nasty } \\
\text { way on the internet }\end{array}$ & $36 \%$ \\
\hline $\begin{array}{l}\text { Having contact on the internet with someone } \\
\text { that your child had not met face-to-face } \\
\text { before }\end{array}$ & $35 \%$ \\
\hline $\begin{array}{l}\text { Spending excessive time on the internet } \\
\text { Seeing or receiving messages that attack } \\
\text { certain groups or individuals (e.g. people of } \\
\text { different colour, religion or nationality) }\end{array}$ & $26 \%$ \\
\hline \begin{tabular}{l} 
Other \\
\hline
\end{tabular} & $31 \%$ \\
\hline
\end{tabular}

Base: All respondents (2061).

When asked which of these risks they would be most concerned about, parents indicated sharing of nudes (19\%). This finding might reflect, to some degree, the way media outlets report stories regarding the pervasiveness of "sexting" among teenagers. However, as a Netsafe (2017) study shows, while there is pressure to share nudes, only a small proportion (4\%) of New Zealand teens (aged 14 to 17 years old) has engaged in this activity.

Parents' concerns varied according to the age of their child. For example, worries about seeing sexual images or videos of someone naked were higher among parents of 9 to 11year-old children. In contrast, parents of 15- to 17-year-olds were significantly less concerned about this situation. On the other hand, parents of 15-year-olds rated lower the sharing of nudes compared to parents of other age groups.

Also, compared to parents of younger children (aged 9-11), parents of older children especially those aged 16 years old - were more concerned about their kids treating someone else in a hurtful or nasty way online.

We found a similar pattern regarding privacy. Parents of older children, especially those aged 17 years old, were more worried about their children having their personal data accessed or misused by someone else. In contrast, parents of younger children, especially those aged 9 and 10 years old, rated this issue lower. On the other hand, parents of 13- and 14-year-olds expressed more concern about their child meeting faceto-face with someone they first got to know on the internet.

A look at the data regarding children's gender revealed that girls' parents were more concerned than parents of boys about them sharing nude images or videos of themselves with others. Meanwhile, boys' parents were more worried than those of girls about their children treating someone else in a hurtful or nasty way online and spending excessive time on the internet. Differences regarding other online safety issues related to gender were not significant.

When looking at children's ethnicity some differences were also found among survey respondents. For instance, parents of NZ European/Pākehā, Māori, and Pacific children were significantly more worried about their children sharing nudes of themselves. On the other hand, having contact with a stranger online was consistently rated highly as a concern by parents of all ethnicities except those of European/Pākehā children. On the other hand, it was more common for parents of Asian children to be worried about their child spending excessive time on the internet. 


\section{AWARENESS OF CHILD'S EXPOSURE TO SEXUALLY EXPLICIT CONTENT}

Next, we asked parents whether they were aware of any exposure of their child to sexually explicit content online in the prior year. Over half of parents (54\%) said "no" while $19 \%$ responded affirmatively to the question. About a quarter of parents (27\%) were not sure whether their child was exposed to sexually explicit content - see Figure 1 for details.

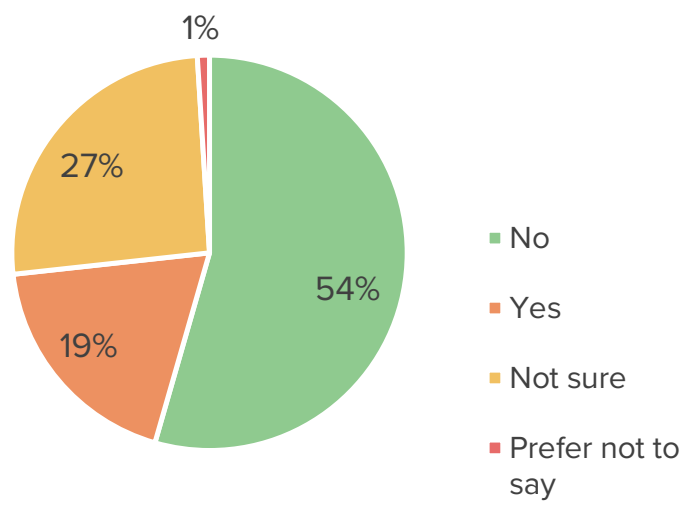

Figure 1. Parents' awareness of their child's exposure to sexually explicit content

\section{Base: All respondents (2061).}

The levels of children's exposure to sexually explicit content reported by parents steadily increases with age. For example, $10 \%$ of parents whose child was aged 9 years old reported being aware their child was exposed to sexual content online in the prior year. The figures gradually increased to $26 \%$ among parents of teens aged 17 years old. Details are presented in Figure 2. Note that the labels 'not sure' and 'prefer not to say' are not included to facilitate graphical interpretation of exposure to sexually explicit content findings.

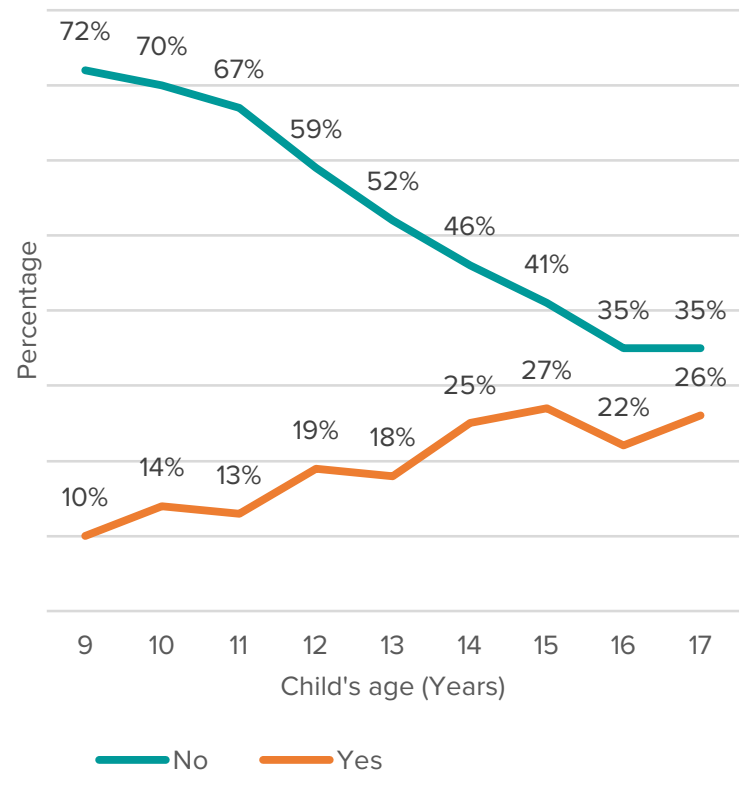

Figure 2. Parents' awareness of their child's exposure to sexually explicit content by children's age

Base: All respondents (2061).

Differences regarding the ethnicity of the children were not statistically significant in our data. However, there was a difference in parents' awareness of exposure in relation to their child's gender. According to parents, boys seemed to be more commonly exposed to sexually explicit content than girls. In this respect, reports about exposure were higher among parents of male children (22\%) compared to those of female children (16\%). See Figure 3.

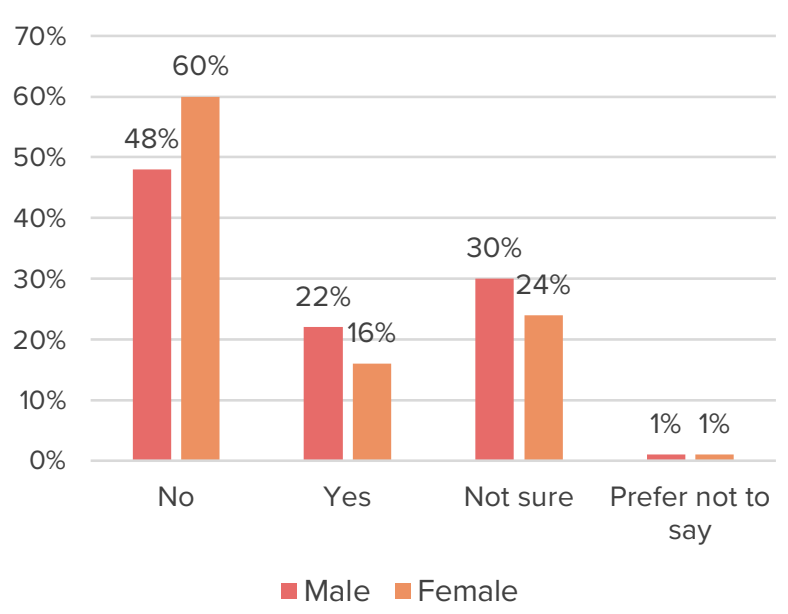

Figure 3. Parents' awareness of their child's exposure to sexually explicit content by children's gender

Base: All respondents (2061). 


\section{PARENTS' FIRST REACTIONS TO CHILDREN'S EXPOSURE}

Through a follow-up question, we also wanted to know what the first reaction of parents was when they found out their child was exposed to sexually explicit content (Figure 4). Of those 382 parents, 39\% indicated that they stayed calm. A different reaction was described by $22 \%$ of respondents who said they were angry or upset about what happened. The third most common reaction was to ignore the situation (10\%). It was also interesting that blaming the child for the situation was rare among parents, with only $1 \%$ saying they shamed or punished them.

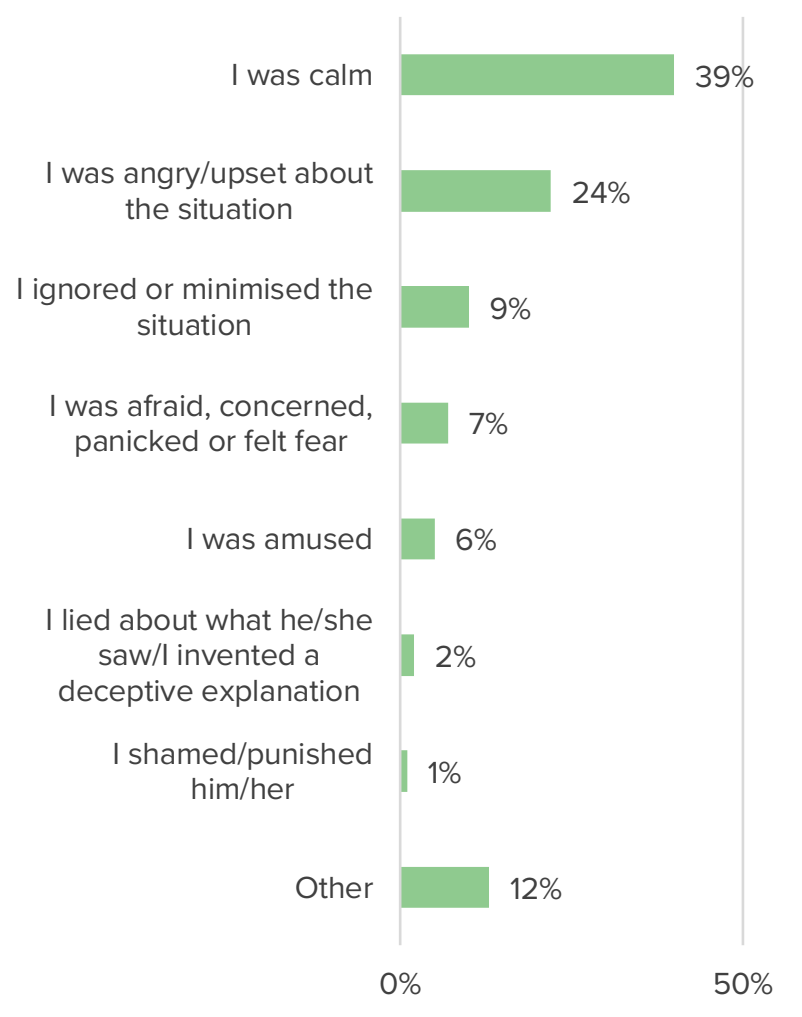

Figure 4. Parents' first reaction

Base: Parents who said their children were exposed to sexually explicit content (382).

When it comes to the age of the children, parents of 16- and 17-year-old teens were significantly more likely to stay calm after finding out about exposure to sexually explicit content online compared to parents of younger children. On the other hand, feeling angry or upset was more common among parents of 13-year-old children and under (an overall 30\%) except for children aged 9 years.

Also, the rate of parents of Māori children who indicated being angry or upset with the exposure situation was higher compared to the responses from parents of children from other ethnicities.

A closer look at the data regarding children's gender also reveals some interesting insights. Parents of girls (31\%), for example, were significantly angrier/more upset about their children's exposure to sexually explicit content compared to parents of boys (19\%). Also, staying calm was a more common first reaction among parents of boys (43\%) than parents of girls (34\%). See Figure 5 for further details.

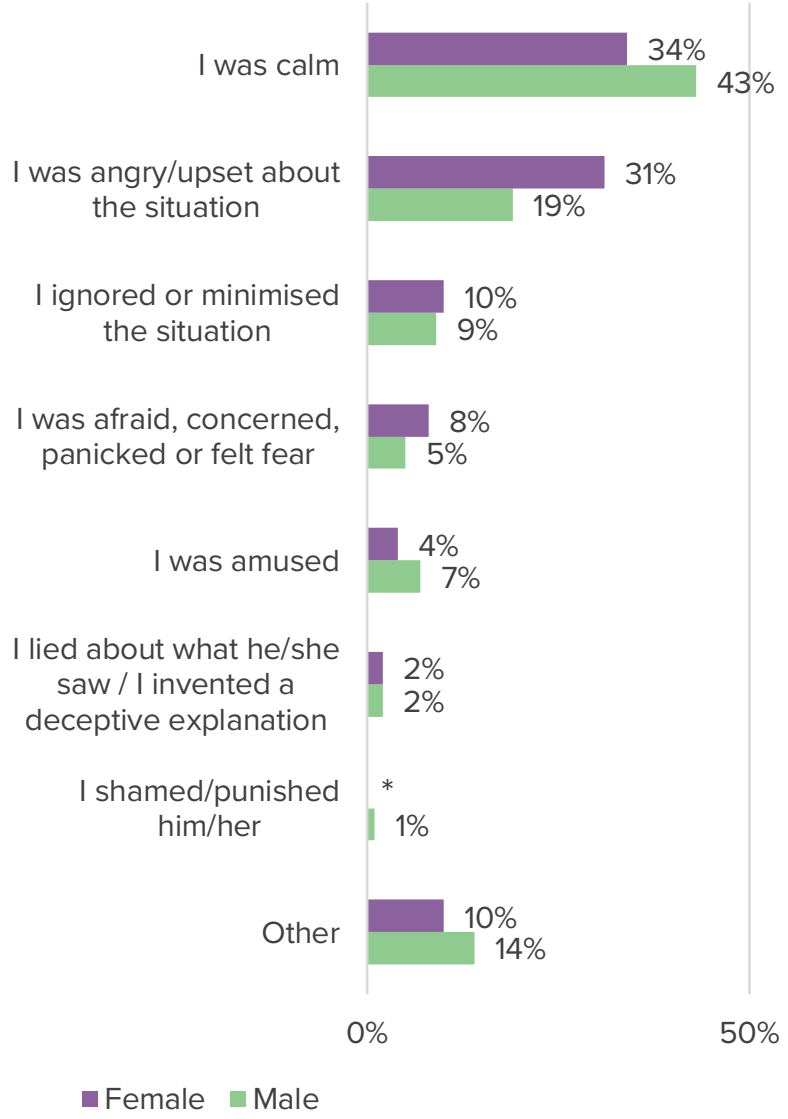

Figure 5. Parents' first reaction by children's gender

Base: Parents who said their children were exposed to sexually explicit content (382).

*Non-statistically relevant number of responses retrieved 


\section{PERCEPTIONS OF CHILDREN'S REASONS FOR EXPOSURE TO SEXUALLY EXPLICIT CONTENT}

We sought to capture parents' perceived reasons for their child's exposure to sexually explicit content. We presented to them a list of potential explanations and allowed them to choose one or more reasons. According to parents the three top reasons explaining their kid's exposure to the content were: sexual content popped up on the screen or device $(32 \%)$, curiosity (30\%), and content was accessed by accident (24\%). Further details are given in Table 2 .

Table 2. Perceived reasons for children's access to sexually explicit content

\section{Reasons for children's access or exposure to sexually explicit content}

\begin{tabular}{|l|c|}
\hline It popped up on the screen/device & $32 \%$ \\
\hline Out of curiosity & $30 \%$ \\
\hline It was accidentally accessed & $24 \%$ \\
\hline Someone sent/shared it with them & $21 \%$ \\
\hline For sexual arousal/stimulation & $10 \%$ \\
\hline For entertainment & $7 \%$ \\
\hline Another reason & $5 \%$ \\
\hline To alleviate boredom/monotony & $2 \%$ \\
\hline To relieve anxiety/stress & $2 \%$ \\
\hline I don't know & $3 \%$ \\
\hline For instructional purposes & $2 \%$ \\
\hline Prefer not to say & - \\
\hline
\end{tabular}

Base: Parents who said their children were exposed to sexually explicit content (382).

Regarding children's ethnicity, perception that exposure was due to content popping up on the screen was more common among parents of Pacifica children in contrast to parents of children of other ethnic groups. Also, parents of Māori children were more likely to think that exposure to this type of content was due to the child's curiosity. Perceptions of exposure due to accidental access to the content were higher among parents of Asian children compared to other ethnic groups. Also, the perception that children were exposed to content because they were seeking sexual arousal/stimulation was higher among parents of NZ European/Pākehā.

On the other hand, parents' perceptions of why their children were exposed to content varied in terms of the child's gender (see Table 3). For example, $42 \%$ of girls' parents thought that content had popped up on the screen and $30 \%$ that it was accidentally accessed. In contrast, boys' parents' rates of these two reasons were significantly lower: $25 \%$ and $20 \%$, respectively.

It was more common for parents of boys to indicate that their child sought out sexually explicit content out of curiosity (37\%) compared to those of girls (20\%). Boys' parents also rated higher other reasons such as seeking sexual arousal, entertainment, and someone else sharing content with the child.

Table 3. Perceived reasons for children's access to sexually explicit content by children's gender

Reasons for children's access or exposure to sexually explicit content

Male Female

\begin{tabular}{|l|c|c|}
\hline $\begin{array}{l}\text { It popped up on the } \\
\text { screen/device }\end{array}$ & $25 \%$ & $42 \%$ \\
\hline It was accidentally accessed & $20 \%$ & $30 \%$ \\
\hline Out of curiosity & $37 \%$ & $20 \%$ \\
\hline $\begin{array}{l}\text { Someone sent/shared it with } \\
\text { them }\end{array}$ & $23 \%$ & $18 \%$ \\
\hline Another reason & $5 \%$ & $6 \%$ \\
\hline For sexual arousal/stimulation & $15 \%$ & $4 \%$ \\
\hline I don't know & $2 \%$ & $4 \%$ \\
\hline For entertainment & $10 \%$ & $2 \%$ \\
\hline To alleviate boredom/monotony & $3 \%$ & $1 \%$ \\
\hline To relieve anxiety/stress & $3 \%$ & $1 \%$ \\
\hline For instructional purposes & $2 \%$ & $1 \%$ \\
\hline Prefer not to say & - & - \\
\hline
\end{tabular}

Base: Parents who said their children were exposed to sexually explicit content (382). 


\section{PARENTS' ACTIONS REGARDING THEIR} CHILDREN'S EXPOSURE

Parents usually take some action in response to learning that their child has been exposed to sexually explicit content. We asked them about these actions to manage their children's accidental or intentional exposure to this sort of content.

The most common action adopted by parents was to talk to their child about the content they saw online (72\%). Less frequent but still relevant was to monitor their child's use of devices and the internet (21\%), and restricting access through filtering or blocking software (21\%). Also, 1 in 10 parents indicated they took no action. See Table 4.

Table 4. Parents' actions to manage their children's exposure to sexually explicit content

\begin{tabular}{|l|c|}
\hline $\begin{array}{l}\text { Parents' reaction(s) to exposure to sexually } \\
\text { explicit content }\end{array}$ & $\%$ \\
\hline $\begin{array}{l}\text { I talked with him/her about sexually explicit } \\
\text { content on the internet }\end{array}$ & $72 \%$ \\
\hline $\begin{array}{l}\text { I started monitoring his/her use of devices and } \\
\text { the internet }\end{array}$ & $23 \%$ \\
\hline $\begin{array}{l}\text { I restricted his/her access to sexual content } \\
\text { using filtering or blocking software }\end{array}$ & $21 \%$ \\
\hline $\begin{array}{l}\text { I limited the time he/she spends on the } \\
\text { internet }\end{array}$ & $13 \%$ \\
\hline None - I didn't take any action & $10 \%$ \\
\hline Other & $6 \%$ \\
\hline Prefer not to say & - \\
\hline
\end{tabular}

Base: Parents who said their children were exposed to sexually explicit content (382).

Overall, when looking at the child's gender, there were no significant statistical differences in relation to parents' actions, except for restricting access to content via filtering or blocking software. In this respect, parents of boys (26\%) were more likely to take this type of action than parents of girls (14\%).

On the other hand, regarding the child's age, it was more common for parents of 12-year-olds to limit their time online. The use of filtering or blocking software was, on the other hand, more common among parents of kids aged 11. Parents of 13-year-olds were also more likely to talk with their child about sexually explicit content online than parents with children from other age sub-groups. Finally, parents of 17year-olds were more likely to not to take any action to address their child's exposure to sexually explicit content.

\section{PARENTS' CONFIDENCE IN MANAGING RELATED ISSUES}

In general, parents expressed high levels of confidence on issues related to their children's exposure to sexually explicit content.

More than 7 in 10 parents (72\%) said they know what to do if their children see or are exposed to sexually explicit content while $17 \%$ responded negatively. Nearly 8 in 10 parents $(78 \%)$ indicated that they know what to say to their children if a situation of exposure to sexual content happens. Over half of parents said they discuss sex education and sexuality with their children, while 3 in 10 do not.

Table 5. Parents' opinions on related issues

\begin{tabular}{|c|c|c|c|}
\hline Related issues & No & Yes & $\begin{array}{l}\text { Not sure/ } \\
\text { Prefer } \\
\text { not to say }\end{array}$ \\
\hline $\begin{array}{l}\text { I know what to do if my } \\
\text { child sees or is exposed } \\
\text { to sexually explicit } \\
\text { content online }\end{array}$ & $17 \%$ & $72 \%$ & $11 \%$ \\
\hline $\begin{array}{l}\text { I know what to say to my } \\
\text { child if they see or are } \\
\text { exposed to sexually } \\
\text { explicit content on the } \\
\text { internet }\end{array}$ & $14 \%$ & $78 \%$ & $8 \%$ \\
\hline $\begin{array}{l}\text { I feel embarrassed talking } \\
\text { with my child about } \\
\text { pornography }\end{array}$ & $71 \%$ & $21 \%$ & $8 \%$ \\
\hline $\begin{array}{l}\text { I have open } \\
\text { discussions/conversation } \\
\text { s about sex and sexuality } \\
\text { with my child }\end{array}$ & $29 \%$ & $63 \%$ & $8 \%$ \\
\hline $\begin{array}{l}\text { I know where to access } \\
\text { parental information and } \\
\text { resources about children } \\
\text { and pornography }\end{array}$ & $38 \%$ & $52 \%$ & $10 \%$ \\
\hline
\end{tabular}

Base: All respondents (2061). 
We also included a couple of statements about "pornography". While most parents (70\%) said they are confident talking with their children about pornography, 2 in 10 reported feeling embarrassed.

While half of parents believed they know where to access parental information and resources about children and pornography, 4 in 10 do not.

Also, parents with children 13 and over were more likely to say yes to: knowing what to do if their child sees sexually explicit content $75 \%$, compared to $70 \%$ of parents with children 12 and under), know what to say to their child if they see explicit content (80\%, compared to $75 \%)$, having open discussions about sex with their child (69\%, compared to 55\%) and knowing where to access information about children and pornography (56\%, compared to $46 \%$ ).

Meanwhile, fathers were less likely than mothers to feel comfortable talking with their child about pornography (66\% no, compared to $73 \%$ of mothers) or to have open conversations about sex with their child (56\% yes, compared to $66 \%$ of mothers). Asian parents are less likely to know what to do $(24 \%)$ or say $(22 \%)$ to their child if they are exposed to sexually explicit content and less likely to have open conversations about sex with their child (43\%).

\section{Concluding remarks}

This summary report has presented findings from a representative survey on parents' awareness and attitudes towards children's exposure to sexually explicit content.

Our findings describe that parents are generally more concerned about the risks associated with sex-related online behaviours of their children than other types of risk. Issues such as the sharing of nudes and exposure to sexually explicit content are among the top three parental concerns in New Zealand. As previously described, these findings might reflect the impact of current news media coverage and public discourse on New Zealand parents' views. However, it is not yet clear whether there is any other contextual factor influencing parents' concerns about the risks of sex-related online behaviours of their children.

The study also offers valuable insights about parents' awareness of their child's exposure to sexually explicit content. As previously reported, $19 \%$ said their child has seen this type of material in the prior year. Compared with a similar Australian study ${ }^{3}$, New Zealand parents report a lower level of awareness about exposure. Another interesting finding relates to parents reporting that overall their child's exposure was more often accidental than intentional.

However, the level of parents' awareness in comparison with their child's actual exposure to sexually explicit content is still unknown in New Zealand. This is mainly because of the methodological and ethical issues around the sensitivity of the topic and collecting data from younger children.

Nevertheless, and interestingly, there are some indications of disparity among parents' level of awareness and teenagers' selfreported exposure to sexually explicit content in the New Zealand context. When looking at a specific age group, our data show that around $25 \%$ of parents of teens aged 14 to 17 years old indicated awareness of their child's exposure in the last 12 months (see Figure 2). However, the recent representative study conducted by the Office of Film and Literature Classification (2018) shows that over two thirds of teens (67\%) of the same age range said they have seen pornography at some point in their lives, and $27 \%$ in the last 6 months. While the literature has already highlighted parents' apparent underestimation and/or unawareness of children's experiences of online risks (Byrne et al., 2014; Livingstone et al., 2011), these 
results together are surprising and call for further exploration of the topic.

Once parents became aware that their child had been exposed to sexually explicit content, most $(72 \%)$ talked with them about the situation. This finding indicates parents' preference for actively mediating their children's internet experience over restrictive and technical actions such as content blocking (Livingstone et al., 2011). This finding is accompanied by the significant level of confidence parents have regarding what to do and say to their child after the event. However, while a parental response that promotes open communication can have positive outcomes for children (see Netsafe, 2018b), we still know little about the quality of these sexuallyexplicit-content-related conversations and the information parents shared with their child.

Our findings also suggest that more needs to be done to enhance digital parenting in New Zealand. There are still significant numbers of parents who feel embarrassed talking about pornography or struggle having an open conversation about sex with their child. Parents' need for information and resources about children and pornography is even more apparent in our data. Prior research suggests that there are barriers preventing some parents addressing issues related to exposure to sexually explicit content: limited sexual health knowledge, believing adolescents are not ready to discuss sex, discomfort discussing sex, and demographic factors (Malacane \& Beckmeyer, 2016). Whether these and other barriers play a role among New Zealand parents is a matter for future research.

Clearly, the findings of this study have implications for digital parenting in New Zealand. We believe that they not only complement the growing body of knowledge about pornography and children but also contribute to the understanding of the role played by New Zealand parents in regard to the topic and the online safety of their children in general.

\section{What's next?}

This summary report is the first instalment from a larger research project. In the upcoming months Netsafe will release findings from its study on New Zealand children and adolescents' access to and use of digital technologies as well as experiences of online risks. The study is part of Netsafe's work as a member of Global Kids Online, an international research network which seeks to generate and sustain rigorous cross-national evidence about children's engagement with their online environment.

Also, we have released a joint report with comparison of findings about exposure to sexually explicit content in the UK, Australia and New Zealand ${ }^{4}$. This report is the result of an international partnership between the UK Safer Internet Centre, the Australian Office of the eSafety Commissioner, and Netsafe.

\section{Acknowledgements}

We would like to thank our international partners for all their work alongside us on this project: Joseph Di Gregorio and Joe Lasco (Office of the eSafety Commissioner, Australia), David Wright (UK Safer Internet Centre) and Professor Andy Phippen (University of Plymouth, UK).

Our gratitude also goes to Colmar Brunton's Ian Binnie and Lisa Neilsen for their contribution to the development of the survey and early analysis of findings, and to Henry Talbot and Sue Hoyle at the Office of Film and Literature Classification and Angela Webster (MA) at Netsafe for their valuable feedback at different stages of this study. The views and interpretations expressed in this report are those of Netsafe. 


\section{Further Resources}

Netsafe provides a range of resources and services to support the online safety and security of all New Zealanders. For resources on parenting and pornography, see:

https://netsafe.org.nz/porn-advice-parents/

https://netsafe.org.nz/online-porn/

\section{References}

Anderson, M. (2016). Parents, teens and digital monitoring. Retrieved June 18, 2018, from http://www.pewinternet.org/2016/01/07/parentsteens-and-digital-monitoring/

Broadcasting Standards Authority, \& NZ On Air. (2015). Children's media use study. Retrieved from http://www.nzonair.govt.nz/research/allresearch/childrens-media-use-study-2015/

Byrne, S., Katz, S. J., Lee, T., Linz, D., \& Mcllrath, M. (2014). Peers, predators, and porn: Predicting parental underestimation of children's risky online experiences. Journal of ComputerMediated Communication, 19(2), 215-231. https://doi.org/10.1111/jcc4.12040

Campbell, M. (2016). Kids who watch porn won't necessarily turn into sex offenders. Retrieved from https://theconversation.com/kids-whowatch-porn-wont-necessarily-turn-into-sexoffenders-67628

Dines, G. (2018). Parents need to start talking to their tweens about the risks of porn. Retrieved February 20, 2018, from https://theconversation.com/parents-need-tostart-talking-to-their-tweens-about-the-risks-ofporn-91888

Flood, M. (2009). The harms of pornography exposure among children and young people. Child Abuse Review, 18(6), 384-400. https://doi.org/10.1002/car.1092

Horvath, M., Alys, L., Massey, K., Pina, A., Scally, M., \& Adler, J. (2013). "Basically... porn is everywhere" A rapid evidence assessment on the effects that access and exposure to pornography has on children and young people. Retrieved from https://www.mdx.ac.uk/_data/assets/pdf_file/0 026/48545/BasicallyporniseverywhereReport.p df

Lim, M. S. C., Carrotte, E. R., \& Hellard, M. E. (2016). The impact of pornography on gender-based violence, sexual health and well-being: what do we know? Journal of Epidemiology and
Community Health, 70(1), 3-5. https://doi.org/10.1136/jech-2015-205453

Livingstone, S. (2017). No, the internet is not actually stealing kids' innocence. Retrieved from https://theconversation.com/no-the-internet-isnot-actually-stealing-kids-innocence-80543

Livingstone, S., Haddon, L., Görzig, A., \& Ólafsson, K. (2011). Risks and safety on the internet: The perspective of European children: Full findings and policy implications from the EU Kids Online survey of 9-16 year olds and their parents in 25 countries. Retrieved September 5, 2017, from http://eprints.Ise.ac.uk/33731/

Malacane, M., \& Beckmeyer, J. J. (2016). A review of parent-based barriers to parent-adolescent communication about sex and sexuality: Implications for sex and family educators. American Journal of Sexuality Education, 1(1), 27-40. https://doi.org/10.1080/15546128.2016.1146187

McCormack, M., \& Wignall, L. (2017). Enjoyment, exploration and education: Understanding the consumption of pornography among young men with non-exclusive sexual orientations. Sociology, 515), 975-991. https://doi.org/10.1177/0038038516629909

Netsafe. (2017). Teens and "sexting" in New Zealand: Prevalence and attitudes. Wellington, New Zealand. https://doi.org/10.2139/ssrn.3128598

Netsafe. (2018a). New Zealand teens' digital profile: A Factsheet. Wellington, New Zealand. https://doi.org/10.2139/ssrn.3134305

Netsafe. (2018b). New Zealand teens and digital harm: Seeking and accessing support. Wellington, New Zealand. https://doi.org/10.2139/ssrn.3208456

Netsafe. (2018c). New Zealand teens and digital harm: Statistical insights into experiences, impact and response. Wellington, New Zealand. https://doi.org/10.2139/ssrn.3188608

Office of Film and Literature Classification. (2018). $N Z$ Youth and Porn: Research findings of a survey on how and why young New Zealanders view online pornography. Wellington, New zealand: Office of Film and Literature Classification.

Owens, E. W., Behun, R. J., Manning, J. C., \& Reid, R. C. (2012). The impact of internet pornography on adolescents: A review of the research. Sexual Addiction \& Compulsivity, 19(1-2), 99122. https://doi.org/10.1080/10720162.2012.660431 
Peter, J., \& Valkenburg, P. M. (2016). Adolescents and pornography: A review of 20 years of research. The Journal of Sex Research, 53(4-5), 509-531.

https://doi.org/10.1080/00224499.2016.1143441

Rothman, E. F., Paruk, J., Espensen, A., Temple, J. R., \& Adams, K. (2017). A qualitative study of what US parents say and do when their young children see pornography. Academic Pediatrics, 178), 844-849.

https://doi.org/10.1016/j.acap.2017.04.014

Short, M. B., Black, L., Smith, A. H., Wetterneck, C. T., \& Wells, D. E. (2012). A review of internet pornography use research: Methodology and content from the past 10 years.

Cyberpsychology, Behavior, and Social

Networking, 15(1), 13-23.

https://doi.org/10.1089/cyber.2010.0477

Zurcher, J. D. (2017). Exploring descriptive norms of parent-child communication about pornography among parents of middle-schoolers in the US. Journal of Children and Media, 114), 381-398. https://doi.org/10.1080/17482798.2017.1312471

\section{CHILDREN'S EXPOSURE TO SEXUALLY EXPLICIT CONTENT: PARENTS' AWARENESS, ATTITUDES AND ACTIONS}

Wellington, New Zealand, December 2018

www.netsafe.org.nz

research@netsafe.org.nz

Recommended citation: Netsafe. (2018). Children's exposure to sexually explicit content: Parents' awareness, attitudes and actions. Retrieved from: https://www.netsafe.org.nz/parents-and-sexually-explicit-content-2018

ISBN: 978-0-473-46556-8

\section{ATTRIBUTION-NONCOMMERCIAL-SHAREALIKE}

https:/ /creativecommons.org/licenses/by-nc-sa/4.0/ [English]

https://creativecommons.org/licenses/by-nc-sa/4.0/legalcode.mi [Te Reo Māori] 